Int. J. Electrochem. Sci., 14 (2019) 9468 - 9481

\title{
Dissolution of Iron and Ionisation of Hydrogen in Borate Buffer under Cyclic Pulse Polarisation
}

\author{
A.I. Marshakov*, A.A. Rybkina
}

A.N. Frumkin Institute of Physical Chemistry and Electrochemistry, Russian Academy of Sciences, Moscow, Russia

*E-mail: mar@ipc.rssi.ru

doi: $10.20964 / 2019.10 .04$

Received: 4 July 2019/ Accepted: 7 August 2019 / Published: 30 August 2019

The dissolution of iron in a neutral borate buffer under cyclic pulse polarisation was studied. If the potential is cycled between the values that correspond to the pre-passivity of iron and cathodic hydrogen evolution, the rate of metal dissolution decreases while the external anodic current increases with the frequency and amplitude of the signal. We consider the reasons for which the anodic current changes with time after the potential is switched and show that the initial segments of current transients correspond to a'solid-state diffusion-phase-boundary kinetics, mixed rate control'mechanism of hydrogen extraction from the metal. The assumption is made that the decrease in the iron dissolution rate under the cyclic pulse polarization is due to the inhibiting effect of atomic hydrogen.

Keywords: dissolution of iron, ionization of hydrogen, potential pulse, chronoamperometry

\section{$\underline{\text { FULL TEXT }}$}

(C) 2019 The Authors. Published by ESG (www.electrochemsci.org). This article is an open access article distributed under the terms and conditions of the Creative Commons Attribution license (http://creativecommons.org/licenses/by/4.0/). 